\title{
Solid Freeform Fabrication
}

\author{
DAVID L. BOURELL $\mathbb{B}^{1,2}$ \\ 1.-Department of Mechanical Engineering, University of Texas, Austin, TX 78712, USA. \\ 2.-e-mail: dbourell@mail.utexas.edu
}

The 2018 Annual International Solid Freeform Fabrication (SFF) Symposium-An Additive Manufacturing (AM) Conference was held August 13-15, 2018 in Austin, Texas, USA. It was attended by 680 researchers, who presented almost 500 technical presentations. The 13 papers in this issue represent outstanding papers from the conference and demonstrate the variety and richness of the field. The 2018 conference proceedings includes an additional 198 manuscripts. These papers, along with 2235 manuscripts from the preceding SFF Symposia from 1990 to 2017 , are available for download free of charge at http://sffsymposium.engr.utexas.edu/archive.

As the papers in this special topic indicate, materials issues in additive manufacturing (AM) present significant challenges as well as opportunities for science-based solutions. Materials impact all parts of AM processing, including formulation of feedstock (Carrion et al.), manufacturability (Bartolai et al.; Gong et al.; Y. Zhang et al.), part characterization (Bartolai et al.; Borish et al.), and part performance (Olakanmi et al.; Richter et al.; Wudy and Drummer). Melt pool dynamics and modeling (Mazzoleni et al.; Rauniyar and Chou) impact part processability and quality. The breadth of additive manufacturing is reflected in three articles dealing with repair (X. Zhang et al.), microfabrication (Roy et al.), and the biomedical field (Zhou et al.). The papers reflect ongoing research from around the world, including the USA, Europe (Italy, Germany), Africa (Botswana), and Asia (China). Four ASTM 52900 process categories are investigated: powder bed fusion, directed energy deposition, material extrusion, and material jetting. Materials coverage includes metals (Gong et al.; Mazzoleni et al.; Olakanmi et al.; Rauniyar and Chou; Carrion et al.; Richter et al.; X. Zhang et al.; Y. Zhang et al.; Roy et al.) and polymers (Bartolai et al.; Borish et al.; Wudy and Drummer; Zhou et al.).

David L. Bourell is the guest editor for the invited topic Solid Freeform Fabrication in this issue.
As a materials and $\mathrm{AM}$ community, we have made a lot of progress, but there remain areas requiring research and development to fully realize the great benefits offered by this incredible collection of advanced processes. The papers in this special topic illustrate this.

The discussion will continue at the 30th Anniversary SFF Symposium, set for August 12-14, 2019 in Austin, Texas, USA. The abstract submission deadline is April 15, 2019. The conference website is http://sffsymposium.engr.utexas.edu/.

The following list summarizes the papers being published under the topic of "Solid Freeform Fabrication". To download any of the papers, follow the URL http://link.springer.com/journal/11837/71/3/pa ge/ 1 to the table of contents page for the March 2019 issue (vol. 71 no. 3).

- "Full-Field Strain Measurement of Material Extrusion AM Parts with Both Solid and Sparse Infill Geometry" by Joseph Bartolai, Alexander E. Wilson-Heid, Jordan R. Kruse, Allison M. Beese, and Timothy W. Simpson.

- "Comparison of Stainless Steel 316L Parts Made By FDM-Based and SLM-Based Additive Manufacturing Processes" by Haijun Gong, Dean Snelling, Kamran Kardel, and Andres Carrano.

- "Effect of Process Parameters on Mechanical Properties of Wire and Arc Additive Manufactured $\mathrm{AlCu}_{6} \mathrm{Mn}$ ” by Yazhou Zhang, Ming Gao, and Xiaoyan Zeng.

- "Defect Identification and Mitigation via Visual Inspection in Large-Scale Additive Manufacturing" by Michael Borish, Brian K. Post, Alex Roschli, Phillip C. Chesser, Lonnie J. Love, and Katherine T. Gaul.

- "Microstructural Characteristics, Crack Frequency, and Diffusion Kinetics of Functionally Graded Ti-Al Composite Coatings: Effects of Laser Energy Density (LED)" by Eyitayo Olatunde Olakanmi, M. Sepako, J. Morake, S.E. Hoosain, and S.L. Pityana.

- "Effect of Initial Surface Features on Laser Polishing of a Co-Cr-Mo Alloy Made by Powder- 
Bed Fusion” by B. Richter, N. Blanke, C. Werner, F. Vollertsen, and F.E. Pfefferkorn.

- "Infiltration Behavior of Thermosets for the Use in a Combined Selective Laser Sintering Process of Polymers" by Katrin Wudy and Dietmar Drummer.

- "Investigation of External Illumination Strategies for Melt Pool Geometry Monitoring in Selective Laser Melting (SLM)" by L. Mazzoleni, L. Caprio, M. Pacher, A.G. Demir, and B. Previtali.

- "Melt Pool Analysis and Mesoscale Simulation of Laser Powder Bed Fusion Process (L-PBF) with Ti-6Al-4V Powder Particles" by Santosh K. Rauniyar and Kevin Chou.

- "Experimental Characterization of a Direct Metal Deposited Cobalt-Based Alloy on Tool
Steel for Component Repair" by Xinchang Zhang, Tan Pan, Wei Li, and Frank Liou.

- "Electrospinning 3D Nanofiber Structure of Polycaprolactone Incorporated with Silver Nanoparticles” by George Z. Tan, Yingge Zhou, Mahesh Thakurathi, and Edward L. Quitevis.

- "Powder Recycling Effects on the Tensile and Fatigue Behavior of Additively Manufactured Ti6Al-4V Parts" by Patricio E Carrion, Arash Soltani-Tehrani, Nam Phan, and Nima Shamsaei.

- "Experimental Study of the Subsystems in a Microscale Additive Manufacturing Process" by Nilabh K. Roy, Dipankar Behera, Obehi Georgina Dibua, Chee Seng Foong, and Michael Arthur Cullinan. 